\title{
Characteristics and Gender Differences Concerning Pulmonary Hemodynamics in Clawn Miniature Pigs
}

\author{
Ryozo KAMIMURA'1), Kentaro SETOYAMA ${ }^{1)}$, Akira YABUKI²), \\ Junichi TOTTORI ${ }^{3)}$, and Syusaku SUZUKI ${ }^{2}$
}

\begin{abstract}
1)Frontier Science Research Center, Kagoshima University, 8-35-1 Sakuragaoka, Kagoshima-city 890-8520, 2)Department of Veterinary Anatomy, Faculty of Agriculture, Kagoshima University, 1-21-24 Korimoto, Kagoshima-city 890-0065, and ${ }^{3)}$ Japan Farm CLAWN Institute, 3504-157 Hishikari-cho, Kagoshima 895-2701, Japan
\end{abstract}

\begin{abstract}
The characteristics and gender differences of the pulmonary hemodynamic parameters of 16 Clawn miniature pigs were examined and the data were compared with reports concerning dogs and other pig species. The pulmonary systolic, diastolic and mean arterial blood pressures of the mini-pig were slightly higher than those of the dog, respectively, but both the right atrial pressure and pulmonary capillary wedge pressure were within the normal physiological ranges of the dog. Concerning gender differences in hemodynamic parameters of the mini-pig, the female values, except the right atrial pressure, were slightly higher than those of the male, but no significant differences were recognized. The present study results will help pulmonary researchers understand the differences between Clawn miniature pigs and dogs for accurate analysis of experimental results.
\end{abstract}

Key words: Clawn miniature pig, gender differences, hemodynamics

The Clawn miniature pig (the name, Clawn, is derived from the initials of the Central Laboratory of White Nipai) was originally bred from Landrace $\times$ Large White and Göttingen Miniature $\times$ Ohmini pigs (Fig. 1). The Clawn mini-pig is now maintained at Japan Farm CLAWN Institute (Kagoshima, Japan). The disposition of the Clawn miniature pig is gentle and tame, thus, Clawn miniature pigs are available for not only acute studies, but also chronic studies requiring periodic blood sampling or drug administration. Cardiovascular and transplantation research $[1,5,6]$ and parasitological research [14], using Clawn miniature pigs have been performed and these miniature pigs are now frequently being used for endoscopic surgical training [13]. In both cardiovascular and pulmonary researches, dogs have been frequently used. Recently, however, the use of dogs has been gradually decreasing due to ethical concerns. Instead of dogs, researches have begun using miniature pigs and we predict that pulmonary research using Clawn miniature pigs will increase in the future. At present, no data on the pulmonary hemodynamic characteristics of the Clawn

(Received 29 January 2007 / Accepted 18 May 2007)

Address corresponding: R. Kamimura, Frontier Science Research Center, Kagoshima University, 8-35-1 Sakuragaoka, Kagoshima-city 890-8520, Japan 
miniature pig have been reported, and the aim of the present study was to clarify the characteristics and gender differences of the pulmonary hemodynamic parameters of the Clawn miniature pig.

The present study was performed in accordance with the Guidelines for Animal Experimentation of Kagoshima University, Japan.

Animals: Sixteen adult Clawn miniature pigs, weighing 24 to $48 \mathrm{~kg}$ (male 8 , female 8 , mean body weight $32 \mathrm{~kg}$ ), purchased from Japan Farm CLAWN Institute (Kagoshima, Japan) were used in the present study. The animals were kept individually in iron cages in an automatically controlled feeding room (temperature: 22 $\pm 2^{\circ} \mathrm{C}$, humidity: $55 \pm 10 \%$, air exchange: 10 times/h) and were given a commercial standard pig diet (Nissin Marubeni, Tokyo, Japan) of 500-1,000 g/day and tap water ad libitum. After one-week acclimatization, these pigs were used.

Anesthesia and experimental procedures: The pigs were anesthetized with an intramuscular injection (atropine sulfate $0.05 \mathrm{mg} / \mathrm{kg}$, medetomidine $80 \mu \mathrm{g} / \mathrm{kg}$, and ketamine sodium $10 \mathrm{mg} / \mathrm{kg}$ ), and were ventilated mechanically using a respirator (Newport Medical Instruments, California, USA) under $100 \%$ oxygen gas mixed with $1-2 \%$ halothane after tracheal intubation. A 7 Fr Swan-Ganz catheter (Edwards Laboratories, Santa Ana, USA) was introduced into the pulmonary arterial trunk via the right external jugular vein for monitoring cardiac output (CO), right atrial pressure (RAP), pulmonary arterial pressure (PAP) and pulmonary capillary wedge pressure (PCWP). A polyethylene catheter was inserted into the thoracic aorta via the carotid artery for systemic blood pressure (BP) measurement and a pig-tail catheter was introduced to the left ventricle via the right femoral artery for monitoring the left ventricle pressure (LVP) and the LV dp/dt. The $\mathrm{CO}$ was measured by the thermo-dilution method and the other parameters were calculated as follows: the Cardiac index $(\mathrm{CI})=\mathrm{CO} / \mathrm{BW}$, and the pulmonary vascular resistance $(\mathrm{PVR})=($ mean PAP-PCWP $) / \mathrm{CO}$ $\times 80$. The values were expressed as the mean \pm SD . Differences were analyzed by Student's $t$-test and a value of $P<0.05$ was chosen as an indication of statistical significance.

The hemodynamic results of the 16 Clawn miniature pigs of both sexes are presented in Table 1. The gender differences are presented in Table 2. No significant

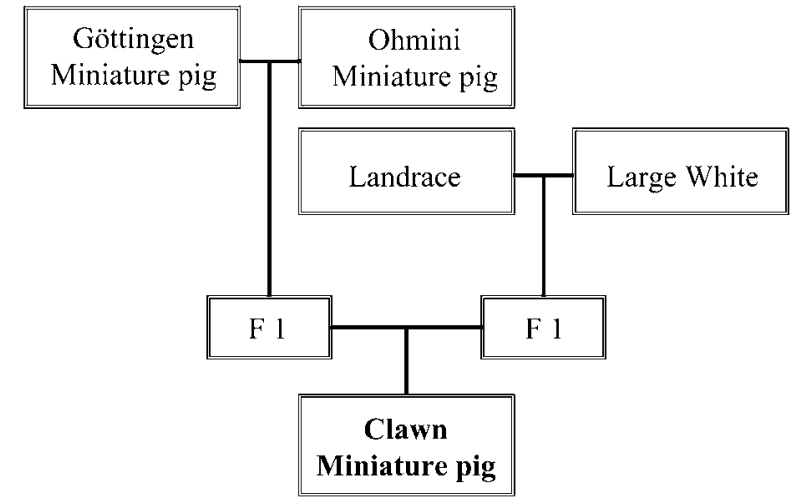

Fig. 1. Origin of the Clawn miniature pig.

Table 1. Hemodynamic variables

\begin{tabular}{lc}
\hline \multicolumn{1}{c}{ Variable } & mean $\pm \mathrm{SD}$ \\
\hline Cardiac index $(\mathrm{ml} / \mathrm{min} / \mathrm{kg})$ & $100 \pm 12$ \\
Systolic arterial pressure $(\mathrm{mmHg})$ & $110 \pm 13$ \\
$\mathrm{LV} \mathrm{dp} / \mathrm{dt}(\mathrm{mmHg} / \mathrm{s})$ & $2,775 \pm 702$ \\
Systolic pulmonary arterial pressure $(\mathrm{mmHg})$ & $35.7 \pm 8.7$ \\
Diastolic pulmonary arterial pressure $(\mathrm{mmHg})$ & $16.2 \pm 6.3$ \\
Mean pulmonary arterial pressure $(\mathrm{mmHg})$ & $22.7 \pm 6.4$ \\
Pulmonary capillary wedge pressure $(\mathrm{mmHg})$ & $9.4 \pm 2.1$ \\
Pulmonary vascular resistance $\left(\right.$ dyne $\left.\cdot \mathrm{s} \cdot \mathrm{cm}^{-5}\right)$ & $316 \pm 119$ \\
\hline & $(\mathrm{n}=16)$
\end{tabular}

differences were recognized between the male and the female pigs. The results of the pulmonary hemodynamic parameters (systolic PAP, diastolic PAP, mean PAP and PCWP in particular) are shown in Fig. 2.

In pulmonary research, such as that focusing on pulmonary hypertension or pulmonary thrombosis, researchers have to fully understand the physiological normal values of the pulmonary hemodynamics and any gender differences that may exist for accurate analysis of the experimental results. Recently, the Clawn miniature pigs have been used in the fields of xenotransplantation [1], parasitology [14] and the cardiovascular research $[5,6]$, and it is expected that in the future, there will be increasing use of Clawn miniature pigs in pulmonary research related to pulmonary hypertension, pulmonary embolism, etc.

Concerning porcine PAP values, Monica reported that the baseline mean PAP of the Large White pig was 25 $\mathrm{mmHg}$ [9] and Patric noted that the PAP of the pig was $24.3 \pm 1.2 \mathrm{mmHg}$ [11]. Furthermore, Baumert demon- 
Table 2. Gender differences of hemodynamic variables

\begin{tabular}{lccc}
\hline \multicolumn{1}{c}{ Variable } & male & female & $\mathrm{p}$ \\
\hline Cardiac index $(\mathrm{ml} / \mathrm{min} / \mathrm{kg})$ & $99 \pm 12$ & $101 \pm 13$ & $\mathrm{NS}$ \\
Systolic arterial pressure $(\mathrm{mmHg})$ & $101 \pm 9$ & $107 \pm 9$ & $\mathrm{NS}$ \\
LV dp/dt (mmHg/s) & $2,562 \pm 654$ & $2,987 \pm 723$ & $\mathrm{NS}$ \\
Systolic pulmonary arterial pressure $(\mathrm{mmHg})$ & $33 \pm 8$ & $38 \pm 8$ & $\mathrm{NS}$ \\
Diastolic pulmonary arterial pressure $(\mathrm{mmHg})$ & $15 \pm 6$ & $17 \pm 6$ & $\mathrm{NS}$ \\
Mean pulmonary arterial pressure $(\mathrm{mmHg})$ & $21 \pm 6$ & $24 \pm 6$ & $\mathrm{NS}$ \\
Pulmonary capillary wedge pressure $(\mathrm{mmHg})$ & $9 \pm 2$ & $10 \pm 2$ & $\mathrm{NS}$ \\
Pulmonary vascular resistance $\left(\right.$ dyne $\left.\cdot \mathrm{s} \cdot \mathrm{cm}^{-5}\right)$ & $286 \pm 115$ & $346 \pm 122$ & $\mathrm{NS}$ \\
\hline
\end{tabular}

Values are mean $\pm \mathrm{SD}$. NS: not significant.

( a)

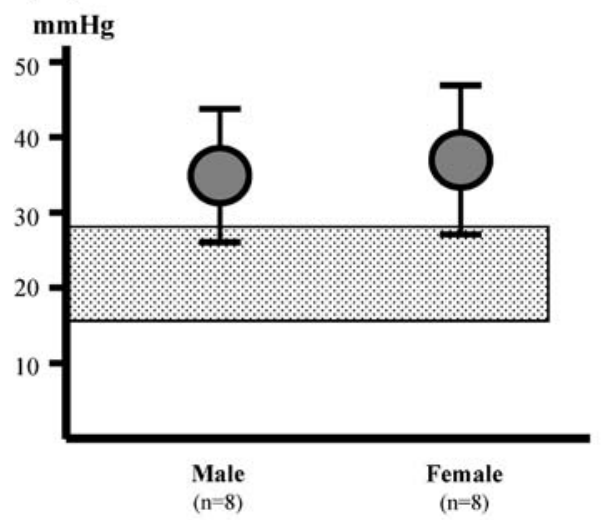

(c)

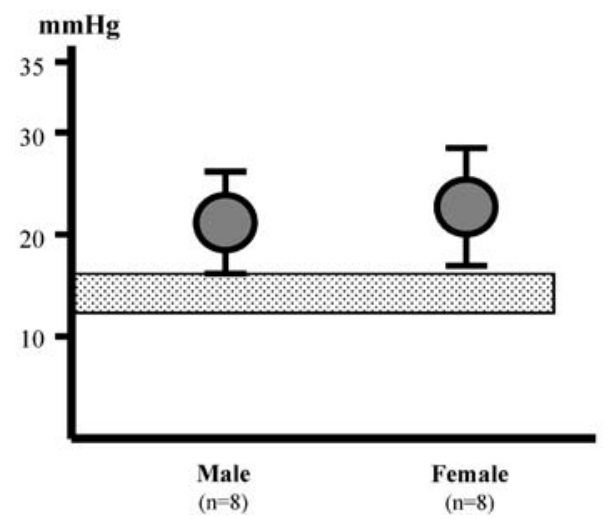

(b)

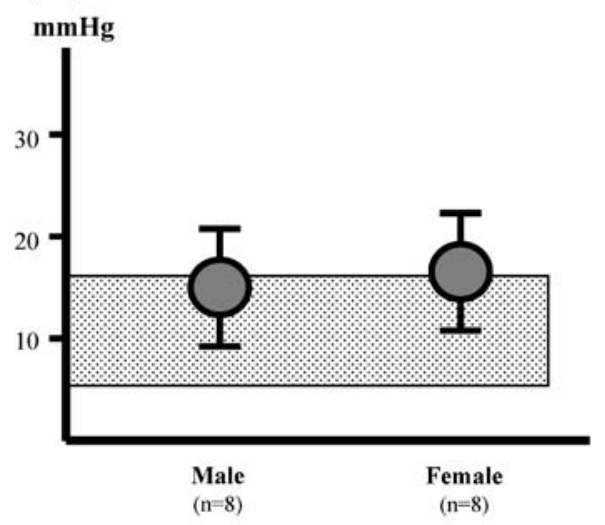

(d)

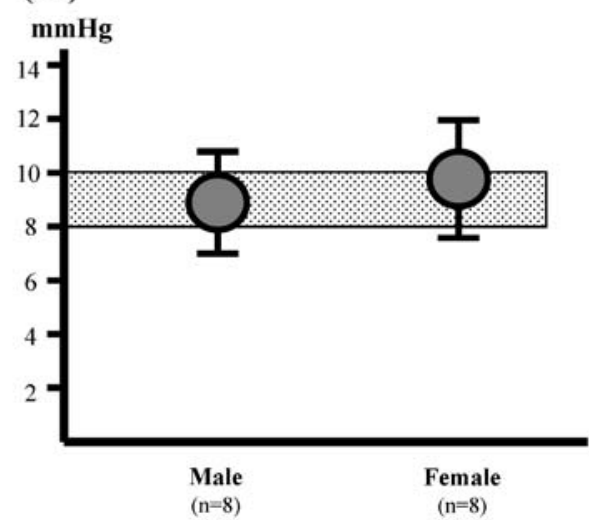

Fig. 2. Pulmonary hemodynamic variables of the Clawn miniature pigs. a) Systolic pulmonary arterial pressure, b) Diastolic pulmonary arterial pressure, c) Mean pulmonary arterial pressure, d) Pulmonary capillary wedge pressure. Values are mean \pm SD. The stippled rectangles represent the normal physiological ranges of the dog (From Ref. 3).

strated that the mean PAP of the Landrace pig was 24 $\pm 6.6 \mathrm{mmHg}$ and the PVR was $318 \pm 147 \mathrm{dyne} \cdot \mathrm{s} \cdot \mathrm{cm}^{-5}$ in his pig pulmonary experiment [2]. But in miniature pigs, Maggiorini reported that some minipigs, compared to dogs, have a higher baseline PAP [7]. There have been no reports detailing the basic physiological data regarding the pulmonary hemodynamics and inherent gender differences of miniature pigs. In the present 
study, we firstly report the PAP, including the systolic PAP, diastolic PAP and the mean PAP, PCWP, RAP and the PVR of the Clawn miniature pig. These values, mean PAP and PVR etc., of the Clawn miniature pigs reported in the present study are in agreement with Baumerts' data. These PAP values are higher than those reported for dogs, but the PCWP and RAP values were within the normal physiological ranges of dogs.

In pulmonary hypertension, the mean PAP is an important indicator for judging the degree of sickness, and the normal canine physiological range of mean PAP is below $20 \mathrm{mmHg}[3,8]$. Although the values of PAP and PVR in the Clawn miniature pigs were higher than those of the upper limit of the normal canine range (PAP $<20 \mathrm{mmHg}$, PVR $<250$ dyne $\cdot \mathrm{s} \cdot \mathrm{cm}^{-5}$ ), the RAP was within the normal canine range $(<6 \mathrm{mmHg})$, and no compensatory hypertrophy of the right ventricle was recognized in postmortem examination. Fugelseth, Nelin and Rock have reported that the PAP rises in hypoxic pig models $[4,10,12]$. However, the miniature pigs of our present study were not in a hypoxic state. Accordingly, we consider that the Clawn miniature pigs used in the present study were physiologically normal and the data obtained from them are suitable as reference data for future research. Concerning gender differences in the pulmonary hemodynamic parameters, we found slight mismatches in the systolic PAP, diastolic PAP, mean PAP and the PCWP, with the female values being slightly higher than those of the male, but without significant difference $(P>0.227)$.

In conclusion, the pulmonary arterial pressure of the Clawn miniature pig is slightly higher than that seen in dogs, and the pulmonary hemodynamics show no differences between males and females. We presume that the reason for the higher PAP found in the Clawn miniature pig is due to the PVR being higher than that of dogs.

\section{References}

1. Ando, A., Ota, M., Sada, M., Katsuyama, Y., Goto, R., Shigenari, A., Kawata, H., Anzai, T., Iwanaga, T., Miyoshi, Y., Fujimura, N., and Inoko, H. 2005. Xenotransplantation 12: 121-126.

2. Baumert, J.H., Hecker, K.E., Hein, M., Reyle-Hahn, M., Horn, N.A., and Rossaint, R. 2005. Br. J. Anaesth. 95: 166-171.

3. Fabrice, B., Simon, T.K., and Eric, M. 2006. Vet. Surg. 35: 252-258.

4. Fugelseth, D., Borke, W.B., Lenes, K., Matthews, I., Saugstad, O.D., and Thaulow, E. 2005. Arch. Dis. Child. Fetal. Neonatal. Ed. 90: 229-234.

5. Kamimura, R., Miura, N., and Suzuki, S. 2003. Exp. Anim. 52: 335-338.

6. Kamimura, R., Suzuki, S., Nozaki, S., Sakamoto, H., Maruno, H., and Kawaida, H. 1996. Exp. Anim. 45: 149153.

7. Maggiorini, M., Mélot, C., Gilbert, E., Vermeulen, F., and Naeije, R. 1998. Respir. Physiol. 111: 213-222.

8. Maria, O.P., Jose, E.T., Maricene, S., Joaquim, F.P., Marco, V.C., Luis, C.M., and Heitor, H. Jr. 2006. Eur. J. Pharmacol. 530: 124-127.

9. Monica, F., Silvia, M., Luciana, A.R., Federica, P., Augusta, Z., Chiara, B., Maria, L.B., and Mariangela, A. 2005. Regul. Pept. 131: 89-96.

10. Nelin, L.D., Moshin, J., Thomas, C.J., Sasidharan, P., and Dawson, C.A. 1994. Pediatr. Res. 35: 20-24.

11. Patrick, S., Serge, B., Nikos, S., Nico, W., Robert, N., Marco, M., and Pascal, V. 1999. Am. J. Physiol. Heart Circ. Physiol. 277: 725-731.

12. Rock, P., Patterson, G.A., Permutt, S., and Sylvester, J.T. 1985. J. Appl. Physiol. 59: 1891-1901.

13. Takao, S., Obara, T., Kamimura, R., Setoyama, K., and Aikoh, T. 2005. Lab. Anim. Technol. Sci. 17: 12-14 (in Japanese).

14. Watanabe, K., Kikuchi, M., Ohno, A., Mohamed, R.T., Nara, T., Ubalee, R., Senba, M., Iwasaki, T., Chen, H., Aoki, Y., and Hirayama, K. 2004. Parasitol. Int. 53: 293299. 